\title{
Hirsutella thompsonii and Pochonia chlamydosporia (Syn. Verticillium chlamydosporium) Mycelia Growth and Predation on Panagrellus redivivus
}

\author{
Cleonice Lubian ${ }^{1}$, Danielle Dutra Martinha ${ }^{2}$, Roberto Luis Portz ${ }^{2}$, Vivian Carré Missio ${ }^{2}$, Luanna Karoline Rinaldi ${ }^{1}$, \\ Tatiane Priscila Chiapetti ${ }^{1}$, Camila Hendges ${ }^{1}$, Maria Eunice Lima Rocha ${ }^{1} \&$ Mayra Taniely Ribeiro Abade ${ }^{1}$ \\ ${ }^{1}$ Universidade Estadual do Oeste do Paraná, Brazil \\ ${ }^{2}$ Universidade Federal do Paraná, Setor Palotina, Brazil \\ Correspondence: Tatiane Priscila Chiapetti, Universidade Estadual do Oeste do Paraná, Brazil. E-mail: \\ tatianechiapetti@gmail.com
}

Received: August 2, 2017

doi:10.5539/jas.v9n11p137

\author{
Accepted: September 15, 2017 \\ Online Published: October 15, 2017 \\ URL: https://doi.org/10.5539/jas.v9n11p137
}

\begin{abstract}
This research aimed to evaluate the nematophagous ability of 4077-Verticillium chlamydosporium var. chlamydosporium and 4466-Hirsutella thompsonii isolates and relate mycelia growth to the influence provoked by movement of nematodes. Each fungus grew in PDA (potato, dextrose, agar) medium end up to pure colonization. Then, ten mycelia plugs of $8 \mathrm{~mm}$ diameter were removed from colony borders and transferred to the center of ten Petri plates containing water-agar $2 \%$ medium. These plates were previously divided into four quadrants that received a number of 25 individuals of free-living nematodes (Panagrellus redivivus), composing a total of 100 nematodes per plate. Evaluations started after 24 hours of interaction, considering predation percentage and mycelia growth as stimuli of nematodes presence. Results showed growing predation performance to both isolates, being higher for $V$. chlamydosporium var. chlamydosporium since from first evaluation time, controlling more than $50 \%$ of nematode population initially added. Its predation potential was $39.2 \%, 38.4 \%$ and $48.35 \%$ higher than $H$. thompsonii at first, second and third evaluation day, respectively. Generally, nematodes did not stimulate mycelia growth, unless for $H$. thompsonii at 72 hours of interaction compared to control plates (without nematodes). Stress resulting from isolates transference from PDA to water-agar 2\% resulted in sparse mycelia growth and it could have affected the predation performance of $H$. thompsonii that controlled nematodes in low levels throughout experiment. Independently of predation level, pictures revealed that both isolates has ability to control P. redivivus through hyphae penetration.
\end{abstract}

Keywords: alternative control, mycelia stimuli, hyphae growth

\section{Introduction}

Biological control of parasitic nematodes represents a viable strategy to minimize chemical application that causes lots of damage in soil biotic microorganisms (Morandi et al., 2009). Among nematophagous microorganisms, fungi are preferred due to their ability on capture and digest nematodes, even free-living ones. In this process, hyphae modifications may occur in some species in order to hold nematodes before preying, changing growth pattern (Chen \& Dickson, 2004). Many fungal species have been continually investigated as a control strategy alternative (Morandi et al., 2009) and the facility in manipulating Panagrellus redivivus turned its use in laboratory trials very common (Sautter et al., 2007).

Members of the genera Hirsutella and Verticillium are filamentous fungi that compose a part of a very diversified group that should succeed better in soil once they can grow even in regions where nutritional sources are scarce (Morley et al., 1996).

Some species belonging to Hirsutella showed ability as biological agents under greenhouse trials (Xiang et al., 2007), as well as Pochonia chlamydosporia (syn. Verticillium chlamydosporium) that releases nematicidal substances (Khambay et al., 2000). Both genera are saprophytic and P. chlamydosporia plays an important role as plant growth promoter (Macia-Vicente et al., 2009). 
As a diversified group, fungi have different feeding pattern, saprophytic absorbs nutrients directly from organic matter and mycorrhizal by association with host plants (Rousk \& Baath, 2011). Fungi survival depends on external carbon source, such as organic acids released by root exudates (Broeckling et al., 2008). Likewise, nematodes can stimulate the activity of some saprophytic fungal species being a nitrogen source to their development (Barron, 2003). Nematodes also may induce modification in mycelia patter growth, as trap formation (Gronvold et al., 1996).

The present study aimed to determine predation of the free-living nematode Panagrellus redivivus by 4077-Verticillium chlamydosporium var. chlamydosporium and 4466-Hirsutella thompsonii isolates and relate mycelia growth to the influence provoked by movement of nematodes.

\section{Material and Methods}

Individuals of Panagrellus redivivus were maintained in a pasty mixture of oat flour and distilled water. Those nematodes climbing the pots were removed with a spatula and put into a Bequer containing distilled water, then they were shaken to get cleaned from flour debris. Afterwards, the solution was poured under a 400 mesh sieve. During this process, nematodes got separated from solution, thus facilitating their capture via pippets. Nematode population was established to allow the extraction of approximately 25 specimens in $20 \mu \mathrm{L}$ of distilled water using an electronic micropipette.

Fungal isolates 4077-Verticillium chlamydosporium var. chlamydosporium and 4466-Hirsutella thompsonii were preserved in the laboratory of phytopathology of Universidade Federal do Paraná, Setor Palotina. Their colonies were cultivated in Petri dishes in potato, dextrose, agar (PDA) medium, stored into body oxygen demand (BOD), at $23.3{ }^{\circ} \mathrm{C}$, under dark condition.

To stimulate growth of mycelia and predation tests, agar plugs $(8 \mathrm{~mm}$ diameter) of pure mycelia grown in PDA were transferred to the center of 10 Petri dishes containing water-agar $(2 \%)$ medium. All Petri dishes were divided into four quadrants and, when mycelia radius expanded $1.5 \mathrm{~cm}$, each quadrant received a media of 25 nematodes. Control dishes were constituted only by pure mycelia without added nematodes. Plates were stored into body oxygen demand (BOD), at $23.3{ }^{\circ} \mathrm{C}$, under dark condition, during experiment.

After $24 \mathrm{~h}$ of nematode-fungi interaction, mycelia growth measuring started in treatments and controls, during three days. This evaluation considered four radial growing (two diametrically opposite) measured with graduated ruler to establish mycelia area colonizing the plates.

For treatments, nematode predation percentage was also analyzed by counting the number of dead nematodes from the population initially added to the plates. Predation status was considered from first colonization signal, as single hyphae penetration, from what on, flight was not possible and full control depended on the time.

Pictures were taken using a cell phone camera of $12 \mathrm{Mp}$ coupled to an optical microscope (Nikon, model ECLIPSE E100 LED). Data were analyzed by a variance analysis (ANOVA) with a significance of $P<0.05$ Tukey media test was applied at 5\% of probability using SISVAR $5.6{ }^{\circledR}$ statistical program (Ferreira, 2011).

\section{Results}

Many studies suggest that nematophagous fungi grow more under high nematode population levels in soils what would lead to a successful rhizosphere colonization. Nevertheless, V. chlamydosporium var. chlamydosporium showed no significant difference in its mycelial growth under nematode presence throughout the experiment (Table 1). H. thompsonii grew more in treatment than in its control with significant difference only after $72 \mathrm{~h}$ of incubation.

Table 1. Mycelia growth (percentage of colonization) for treatment and control (without nematodes) of Hirsutella thompsonii and Verticillium chlamydosporium var. chlamydosporium after 24, 48 and 72 hours

\begin{tabular}{lllll}
\hline & Specie & $24 \mathrm{~h}$ & $48 \mathrm{~h}$ & $72 \mathrm{~h}$ \\
\hline \multirow{2}{*}{ Treatment } & Verticillum chlamydosporium var. chlamydosporium & $46.333 \mathrm{Aab}$ & $50.110 \mathrm{Bb}$ & $54.556 \mathrm{Cc}$ \\
& Hirsutella thompsonii & $44.444 \mathrm{Aab}$ & $45.555 \mathrm{Aa}$ & $47.111 \mathrm{Ab}$ \\
\hdashline Control & Verticillum chlamydosporium var. chlamydosporium & $46.778 \mathrm{Ab}$ & $50.888 \mathrm{Bb}$ & $58.222 \mathrm{Cc}$ \\
& Hirsutella thompsonii & $42.556 \mathrm{Aa}$ & $42.556 \mathrm{Aa}$ & $42.778 \mathrm{Aa}$ \\
\hdashline & 11.120 & 9.980 & 9.900 \\
& C.V. (\%) & 0.037 & 0.000 & 0.000 \\
\hline
\end{tabular}

Note. ${ }^{*}$ Means followed by same small letter in the column and by the same capital letter in the line did not differ significantly from each other, Tukey test, at $5 \%$ probability. 
Related to predation percentage, there was higher performance to V. chlamydosporium var. chlamydosporium than H. thompsonii at any evaluation time (Table 2).

Table 2. Nematodes predation percentage by Hirsutella thompsonii and Verticillium chlamydosporium var. chlamydosporium at 24, 48 and 72 hours of biocontrol interaction

\begin{tabular}{llll}
\hline Specie & $24 \mathrm{~h}$ & $48 \mathrm{~h}$ & $72 \mathrm{~h}$ \\
\hline Verticillum chlamydosporium var. chlamydosporium & $41.20 \mathrm{Aa}$ & $44.60 \mathrm{Aa}$ & $55.95 \mathrm{Ba}$ \\
Hirsutella thompsonii & $2.00 \mathrm{Ab}$ & $6.20 \mathrm{ABb}$ & $7.60 \mathrm{Bb}$ \\
\hdashline $\mathrm{C} . \mathrm{V} .(\%)$ & 24.02 & $25.57^{-}$ & $22.77^{-1}$ \\
$\mathrm{Fc}(\mathrm{Pr}>\mathrm{Fc})$ & 0.00 & 0.00 & 0.00 \\
\hline
\end{tabular}

Note. * Means followed by same small letter in the column and by the same capital letter in the line did not differ significantly from each other, Tukey test, at $5 \%$ probability.

There was no relation between growth area before nematodes addition and predation level to both fungi species. $V$. chlamydosporium var. chlamydosporium grew during 11 days and preyed more than half of nematode population initially added at third day, whereas $H$. thompsonii took 32 days growing on agar, but its predation level kept low anyway (Table 2). V. chlamydosporium var. chlamydosporium grew only $4.008 \% 9.09 \%$ and $13.646 \%$ more than $H$. thompsonii at 24, 48 and $72 \mathrm{~h}$ of biocontrol interaction, but preyed 20.6, 7.193 and 7.362 times more than $H$. thompsonii at same interaction times.

Both isolates preyed nematodes by hyphae penetration (Figures 1 and 2). Hirsutella thompsonii seem to degrade body cell layer first and then absorbs the inner content of body. In some well-degraded nematodes, $V$. chlamydosporium var. chlamydosporium developed reproductive structures over the bodies (Figure 1).
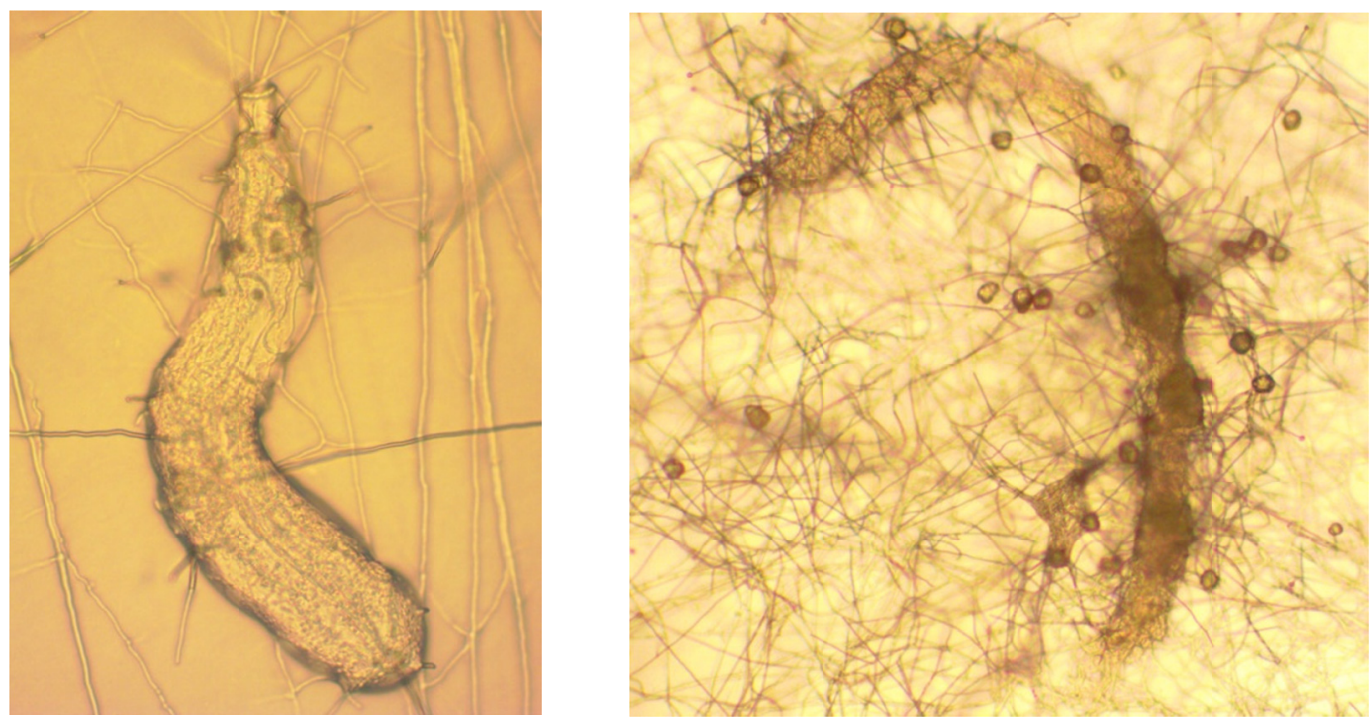

Figure 1. Panagrellus redivivus preyed by the isolate 4077-Verticillium chlamydosporium var. chlamydosporium Note. Images taken by optical microscope using $100 \times$ magnifying objective.

Verticillium chlamydosporium var. chlamydosporium predation kicked off at $24 \mathrm{~h}$ of interaction with hyphae modifications, such as thickening and clewing. First nematodes were captured in $24 \mathrm{~h}$ been intensely surrounded by hyphae (Figure 1). Afterwards nematodes continued been preyed in less accented way. 

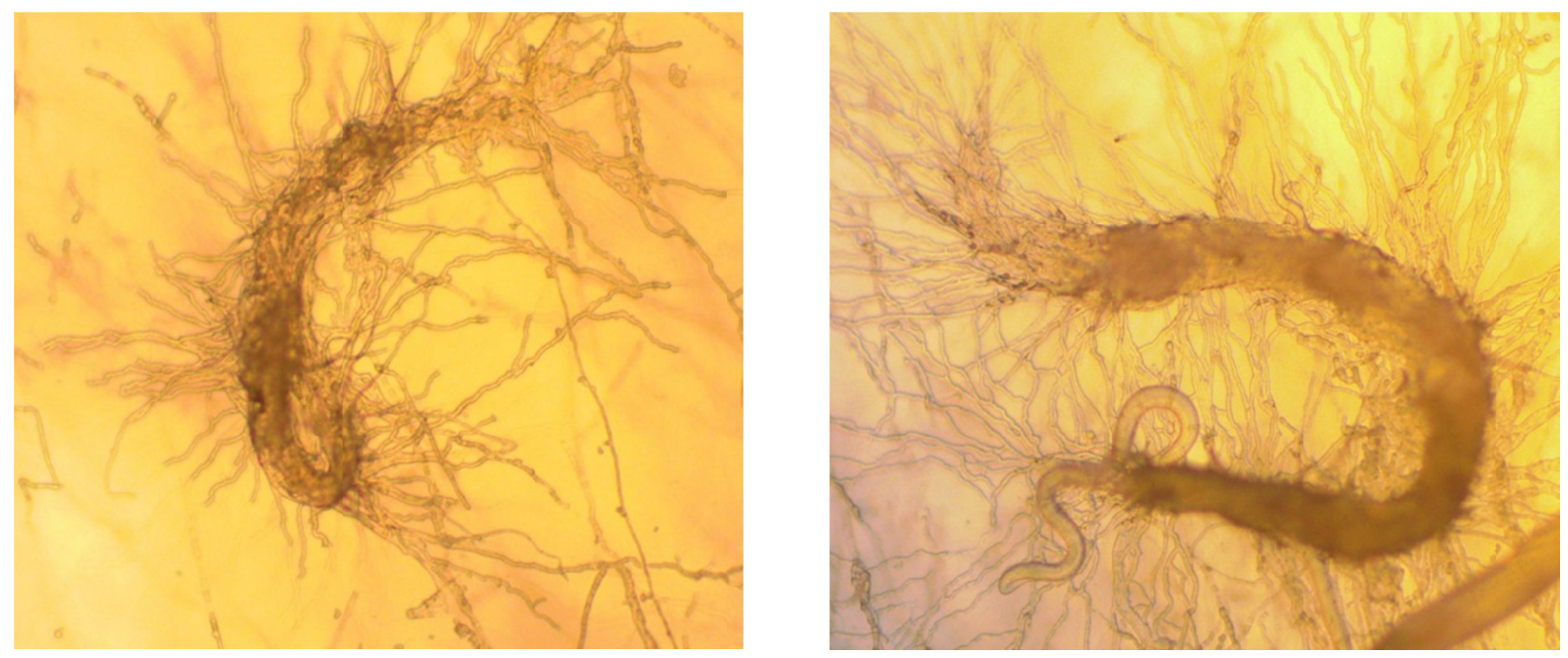

Figure 2. Panagrellus redivivus preyed by the isolate 4466-Hirsutella thompsonii

Note. Images taken by optical microscope using $100 \times$ magnifying objective.

\section{Discussion}

Fungi in control plates grew up at the same rate than treatments. Therefore, growth was not influenced by nematodes presence, as expected (Table 1), unless for H. thompsonii at third evaluation day, which effect was probably random. Therefore, the predation enhance of theses isolates does not rely on nematode as substrate.

Nematodes may cause hyphae modification into trap formation to fungi catch them (Pendse et al., 2013), but not all species can form traps or other capturing devices, moreover, little is related to how fast mycelium extent related to predation.

Nematodes, in general, represent nitrogen nutritional source for fungi growth (Barron, 2003) and there is no study in the literature considering nematodes as stimuli to mycelia growth of biocontrol fungi agents in vitro. Researchers usually evaluate the influence of carbon and nitrogen ratio from different amendments on parasitic ability of nematophagous fungi in greenhouses trials. Luambano et al. (2015) concluded that egg predation ( $M$. incognita) by Pochonia chlamydosporia did not increase in medium richer in carbon content.

The substrate where fungi grow on may change propagules infectiveness. Rossi-Zalaf et al. (2008) determined the effect of substrates on the ability of $H$. thompsonii to colonize Brevipalpus phoenicis. According to them, suitable nutrition was very important to form infectious structures. In this study, fungi were transferred from PDA to water-agar (2\%) medium, less nutritive substrate that caused sparse mycelia growth but none specialized infectious structure were seen. Stress caused by substrate changing possibly affected the predation ability of H. thompsonii more than V. chlamydosporium var. chlamydosporium's (Table 2).

Mycelia growth is related to nematophagous ability (Nordbring, 1998). Studies on influence of nematophagous fungi mycelia growth usually remain related to temperature conditions, as observed by Cadioli et al. (2007). These authors tested 31 isolates of Paecilomyces lilacinus to the following temperatures $20^{\circ} \mathrm{C}, 22.5{ }^{\circ} \mathrm{C}, 25^{\circ} \mathrm{C}$, $27.5^{\circ} \mathrm{C}$ and $30^{\circ} \mathrm{C}$ noticing better growth at $22.5^{\circ} \mathrm{C}$ and better predation on eggs of M. paranaensis at $25^{\circ} \mathrm{C}$. In this study, both isolates grew fine at $23.3{ }^{\circ} \mathrm{C}$ but only $V$. chlamydosporium var. chlamydosporium presented relevant predation levels. It is possible that $H$. thompsonii predation could change in different temperature conditions like for $P$. lilacinus.

Andaló et al. (2008) evaluated predation percentage of Heterorhabditis amazonensis by fungi Arthrobotrys conoides, A. oligospora and Duddingtonia flagrans and noticed that predation speed depended on the mycelia area in Petri plate as well as time mycelia took to establish on agar. Their results related larger mycelia growth before nematode addition to higher predation percentage that occurred after eight days of interaction between fungal and nematodes. Unlikely, our results showed no relation between mycelia area before nematodes addition and predation percentages (Tables 1 and 2).

Obviously, mycelia area is not the only parameter to set predation potential, because both isolates started predation test in similar growth extent (Table 1) although time request for it was different between them. These 
results match with Bourne and Kerry (1999) and Mauchline et al. (2004) who concluded that there is no simple relation between mycelia extent and predation levels.

Mycelia growth and egg parasitism of $M$. javanica by 18 isolates of $P$. lilacinus and three isolates of P. chlamydosporia under five temperatures influence revealed statistical difference (Stroze et al., 2013). However there was no apparent relation between mycelia growing and egg parasitism level at any incubation temperature for $P$. lilacinus. Isolates of $P$. chlamydosporia did not differ to growing parameter at any temperature and egg parasitism was lower for only one isolate at $20^{\circ} \mathrm{C}$.

Greenhouse trials had shown an indirect effect of host plants on fungal development on rhizosphere (Bourne \& Kerry, 1999). Thus, not only artificial medium plays important interference on fungal performance, but also the root plants to which they need to establish any relation to succeed as control agents. Mauchline et al. (2004) analyzed root colonization of three isolates of $P$. chlamydosporia in potato and tomato plants, in both, health or infested conditions. Infested treatments consisted in individual presence of nematodes Globodera rostochiensis or $M$. javanica. Results revealed that one isolate growth was not effected by either nematode species presence. However, one isolate grew more in treatments with $M$. javanica in both plants. In this study, the presence of $P$. redivivus did not stimulate $V$. chlamydosporium var. chlamydosporium growth. These responses suggest high dependence on the fungal isolate to determine how much mycelia growth may be stimulated by different nematode species.

Many studies relate the nematode controlling agents colonization to plant exudate influence or organic matter content preferably than to nematode stimuli. De Leij and Kerry (1991) observed that $V$. chlamydosporium colonization in rhizosphere depends on fungal isolate and plant species, possibly because different plant species produce and release distinct exudates compounds that can improve or inhibit microorganisms association with roots (Haichar et al., 2014).

This lack of stimuli to mycelia growth of $V$. chlamydosporium var. chlamydosporium matches to findings of Quinn (1987) who established that predation activity is more related to the pressure caused on saprophytic ability by others microorganisms in soil than for nematode population density in soil. Here, fungal isolates were set individually to prey nematodes not being possible to observe predation potential under saprophytic pressure.

Nematophagous fungi are classified as predacious, parasitic and opportunistic. Genus Verticillium contains opportunistic individuals, as Paecilomyces. This group of nematophagous agents are considered better over predacious and parasitic ones, due to their ability to colonize eggs and cysts released in soil, preventing larger juvenile infection (Siddiqui \& Mahmood, 1996). In this study, V. chlamydosporium var. chlamydosporium preyed on $P$. redivivus, a free-living nematode whose life cycle does not have eggs or cysts. Therefore, this fungal specie display a role as predacious agent too, once it captures nematodes by hyphae, a characteristic from predacious species.

A chemical study performed by Niu et al. (2010) detected toxicity of two aurovetin compounds obtained from fermented mycelia extract of $P$. chlamydosporia on worms of $P$. redivivus, leading to body disintegration. This chemical support may explain the better performance of $P$. chlamydosporia on preying $P$. redivivus compared to H. thompsonii ability (Table 2).

The ability of fungal agents on controlling nematodes depend on several factors like environment conditions, isolate genetic, host plant, nematode specie and go on. Other details are even more specific, since $V$. chlamydosporium produces proteases that hydrolyses outer layer proteins that compose eggshell of $M$. incognita (Segers et al., 1994). For such reasons, many studies propose a mixture of distinct fungi species or isolates to enhance biological control activity, considering particularities of each living involved. Isolates mix of $P$. chlamydosporia assured additive effect on nematodes eggs reduction Mauchline et al. (2004).

\section{Conclusions}

Panagrellus redivivus did not stimuli mycelia growth of $V$. chlamydosporium var. chlamydosporium at any time while H. thompsonii grew significantly more in presence of nematodes only at third evaluation day.

Both isolates were able to prey nematodes. Predation levels of $V$. chlamydosporium var. chlamydosporium were superior to H. thompsonii in all evaluation times.

\section{Acknowledgements}

Thank you to Pedro Tetsuo Kanno for sharing fungal isolates.

This research was supported by Universidade Federal do Paraná, Setor Palotina. 


\section{References}

Andaló, V., Moreira, G. F., Maximiniano, C., Moino Jr, A., \& Campos, V. P. (2008). Suscetibilidade de Heterorhabditis amazonensis (Rhabditida: Heterorhabditidae) a fungos predadores de nematoides. Nematologia Brasileira, 32(3), 177-184.

Barron, G. L. (2003). Predatory fungi, wood decay, and the carbono cycle. Biodiversity, 4(1), 3-9. https://doi.org/10.1080/14888386.2003.9712621

Bourne, J. M., \& Kerry, B. R. (1999). Effect of the host plant on the effcacy of Verticillium chlamydosporium as a biological control agent of root-knot nematodes at different nematode densities and fungal application rates. Soil Biology and Biochemistry, 31, 75-84. https://doi.org/10.1016/S0038-0717(98)00107-2

Broeckling, C. D., Broz, A. K., Bergelson, J., Manter, D. K., \& Vivanco, J. M. (2008). Root exudates regulate soil fungal community composition and diversity. American Society for Microbiology, 74(3), 738-744. https://doi.org/10.1128/AEM.02188-07

Cadioli, M. C., Santiago, D. C., Hoshino, A. T., \& Homechin, M. (2007). Crescimento micelial e parasitismo de Paecilomyces lilacinus sobre ovos de Meloidogyne paranaensis em diferentes temperaturas in vitro. Ciências e Agrotecnologia, 31(2), 305-311. https://doi.org/10.1590/S1413-70542007000200006.

Chen, S., \& Dickson, D. W. (2004). Biological control of nematodes by fungal antagonists. In Z. X. Chen, S. Y. Chen, \& D. W. Dickson (Eds.), Nematology: Advances and perspectives (Vol. 2, pp. 979-1039). China, Tsinghua University Press: CABI Publishing. https://doi.org/10.1079/9780851996462.0979

De Leij, F. A. A. M., \& Kerry, B. R. (1991). The nematophagous fungus Verticillium chlamydosporium Goddard, as a potential biological control agent for Meloidogyne arenaria (Neal) Chitwood. Revue Nématologie, 14, $157-164$

Ferreira, D. F. (2011). Sisvar: A computer statistical analysis system Sisvar: um sistema computacional de análise estatística. Ciência e Agrotecnologia, 35(6), 1039-1042. https://doi.org/10.1590/S1413-70542011000 600001

Gronvold, J., Nansen, P., Henriksen, S. A., Larsen, M., Wolstrup, J., Bresciani, J., ... Fribert, L. (1996). Induction of traps by Ostertagia ostertagi larvae, chlamydospore production and growth rate in the nematode-trapping fungus Duddingtonia flagrans. Journal of Helminthology, 70(4), 291-297. https://doi.org/10.1017/S0022149X00015571

Haichar, F. E. Z., Santaella, C., Heulin, T., \& Achouak, W. (2014). Root exudates mediated interactions belowground. Soil Biology \& Biochemistry, 77, 69-80. https://doi.org/10.1016/j.soilbio.2014.06.017

Khambay, B., Bourne, J. M., Cameron, S., Kerry, B., \& Zaki, M. (2000). A nematicidal metabolite from Verticillium chlamydosporium. Pest Management Science, 56, 1098-1099. https://doi.org/10.1002/1526-49 98(200012)56:12\%3C1098::AID-PS244\%3E3.0.CO;2-H

Lopes, E. A., Ferraz, S., Ferreira, P. A., Freitas, L. G., Dhingra, O. D., Gardiano, C. G., \& Carvalho, S. L. (2007). Potencial de isolados de fungos nematófagos no controle de Meloidogyne javanica. Nematologia Brasileira, 31(2), 20-26.

Luambano, N. D. Manzanilla-López, R. H., Kimenju, J. W., Powers, S. J., Narla, R. D., Wanjohi, W. J., \& Kerry, B. R. (2015). Effect of temperature, $\mathrm{pH}$, carbon and nitrogen ratios on the parasitic activity of Pochonia chlamydosporia on Meloidogyne incognita. Biological Control, 80, 23-29. https://doi.org/10.1016/ j.biocontrol.2014.09.003

Macia-Vicente, J. G., Rosso, L. C., Ciancio, A., Jansson, H.-B., \& Lopez-Llorca, L. V. (2009). Colonization of barley roots by endophytic Fusarium equiseti and Pochonia chlamydosporia: Effects on plant growth and disease. Annals of Applied Biology, 155, 391-401. https://doi.org/10.1111/j.1744-7348.2009.00352.x

Mauchline, T. H., Kerry, B. R., \& Hirsch, P. R. (2004). The biocontrol fungus Pochonia chlamydosporia shows nematode host preference at the infraspecific level. Mycological Research, 108(2), 161-169. https://doi.org/10.1017/S095375620300889X

Morandi, M. A. B., \& Bettiol, W. (2009). Controle biológico de doenças de plantas no Brasil. In W. Bettiol \& M. A. B. Morandi (Eds.), Biocontrole de doenças de plantas: Uso e perspectivas (Vol. 1, pp. 7-14). Jaguariúna: Embrapa Meio Ambiente.

Morley, G. F., Sayer, J. A., Wilkinson, S. C., Gharieb, M. M., \& Gadd, G. M. (1996). Fungal sequestration, solubilization and transformation of toxic metals. In J. C. Frankland, N. Magan \& G. M. Gadd (Eds.), Fungi 
and Environmental Change (Vol. 1, pp. 235-256). Cambridge University Press, Cambridge. https://doi.org/ 10.1017/CBO9780511753190.016

Niu, X. M., Wang, Y. L., Chu, Y. S., Xue, H. X., Li, N., Wei, L. X., .. Z Zhang, K. Q. (2010). Nematodetoxic aurovertin-type metabolites from a root-knot nematode parasitic fungus Pochonia chlamydosporia. Journal of Agricultural and Food Chemistry, 58, 828-834. https://doi.org/10.1021/jf903259n

Nordbring, B. (1998). Ecology and recognition in the nematode nematophagous fungus system. In K. C. Marshall (Ed.), Advances in Microbial Ecology (Vol. 10, pp. 81-114). New York: Marshall, K. C.

Pendse, M. A., Karwande, P. P., \& Limaye, M. N. (2013). Past, present and future of nematophagous fungi as bioagent to control plant parasitic nematodes. The Journal of Plant Protection Sciences, 5(1), 1-9.

Quinn, M. A. (1987). The influence of saprophytic competition on nematode predation by nematode-trapping fungi. Journal of Invertebrate Pathology, 49, 170-74. https://doi.org/10.1016/0022-2011(87)90157-1

Rossi-Zalaf, L. S., Alves, S. B., \& Vieira, S. A. (2008). Efeito de meios de cultura na virulência de Hirsutella thompsonii (Fischer) (Deuteromycetes) para o controle Brevipalpus phoenicis (Geijskes) (Acari: Tenuipalpidae). Neotropical Entomology, 37(3), 312-320. https://doi.org/10.1590/S1519-566X2008000 300011

Rousk, J., \& Baath, E. (2011). Growth of saprotrophic fungi and bacteria in soil. FEMS Microbiology Ecology, 78, 17-30. https://doi.org/10.1111/j.1574-6941.2011.01106.x

Segers, R., Butt, T. M., Kerry, B. R., \& Peberdy, J. F. (1994). The nematophagous fungus Verticillium chlamydosporium produces a chymoelastase-like protease which hydrolyses host nematode protein in situ. Microbiology, 140, 2715-2723. https://doi.org/10.1099/00221287-140-10-2715

Siddiqui, Z. A., \& Mahmood, I. (1996). Biological control of plant parasitic nematodes by fungi: A review. Bioresource Technology, 58, 229-239. https://doi.org/10.1016/S0960-8524(96)00122-8

Stroze, C. T., Santiago, D. C., \& Baida, F. C. (2013). Isolamento, caracterização e avaliação do potencial de fungos nematófagos no parasitismo de Meloidogyne javanica "in vitro". Nematropica, 43(1), 18-23.

Xiang, N. C., Yang, X. H., Wang, Z. X., Liu, X. Z., Chen, S. Y., \& Xiao, Q. M. (2007). Variability of morphology, parasitism, and nucleotide sequences among isolates and species of nematophagous Hirsutella. Biological Control, 41(1), 110-119. https://doi.org/10.1016/j.biocontrol.2006.12.016

\section{Copyrights}

Copyright for this article is retained by the author(s), with first publication rights granted to the journal.

This is an open-access article distributed under the terms and conditions of the Creative Commons Attribution license (http://creativecommons.org/licenses/by/4.0/). 